\title{
Maternal ophthalmic artery Doppler indices in type 1 diabetes during pregnancy
}

\author{
Gehan Abdelhaleim Abdelhaleim Ahmed, Elsafi Ahmed Abdalla, Caroline Edward Ayad*
}

Radiology Department, Sudan University of Science and Technology, College of Medical Radiological Science, Khartoum, Sudan

\section{Email address:}

dr.elsafi@gmail.com, dr.elsafi@sustech.edu (E.A. Abdalla), gehanhaleem@yahoo.com (G. A. Abdelhaleim), carolineayad@yahoo.com, carolineayad@sustech.edu (C. E. Ayad)

\section{To cite this article:}

Gehan Abdelhaleim Abdelhaleim Ahmed, Elsafi Ahmed Abdalla, Caroline Edward Ayad. Maternal Ophthalmic Artery Doppler Indices in Type 1 Diabetes during Pregnancy. American Journal of Health Research. Vol. 2, No. 3, 2014, pp. 89-92.

doi: 10.11648/j.ajhr.20140203.12

\begin{abstract}
This Study aimed to assess the Doppler indices for ophthalmic artery in type 1diabetic pregnant ladies. Inclusion criteria were 15diabetic pregnant ladies, their ages were (30-39), 14 healthy pregnant non diabetic ladies aged (30-37), and 15 healthy non pregnant non diabetic subjects aged (30-41) were selected as control group. Pregnant ladies with eye disease or pregnancy abnormality or preeclampsia were excluded. Ultrasound examination for both eyes were obtained using 7.5MHZ high resolution ultrasound machine. Readings of Ophthalmic artery Doppler indices (resistive index (RI), pulsatility index (PI)) for type 1 diabetes ladies were found to be greater when compared with the control group values and Mean Velocity (MV) was of lower values. The mean values $\pm \mathrm{SD}$ were as follows: for right eye: resistive index, $1.3 \pm 0.2(P<.005$ Control0.8 \pm 0.1$)$; pulsatility index, $(3.6 \pm 0.4(P<.005$ Control1 $.6 \pm 0.4)$; Mean Velocity (MV) $5.2 \pm 1.1(P<.005$ Control 8.4 $\pm 3.2)$. For left eye resistive index, $1.4 \pm 0.2(P<.005$ Control $0.7 \pm 0.1)$; pulsatility index, $3.3 \pm 0.5(P<.005$ Control $1.6 \pm$ $0.3)$; Mean Velocity (MV) $5.7 \pm 0.8(P<.005$ Control $8.5 \pm 3.2)$. The correlations between the variables and gestational age in the two pregnant groups were studied and were compared with the control group and maternal treatment. The study revealed that the Doppler indices for right and left eyes differed significantly within the three trimesters for pregnant diabetic and pregnant non diabetic ladies and when compared with the control group at p-value $\square 0.05$. No significant difference was detected between the Doppler indices and the treatment taken as Diet Control, or insulin for type 1 diabetic pregnant ladies. Color Doppler Ultrasonography is useful for assessing blood flow. Ophthalmic arteries Doppler Indices were affected significantly in pregnant ladies with or without type 1 diabetes.
\end{abstract}

Keywords: Type 1 Diabetes, Pregnancy, Doppler Ultrasonography

\section{Introduction}

Ophthalmic Arteries circulation has been assessed by Color Doppler Ultrasonography for the last two decades [1].Diabetes is the leading cause of new cases of blindness in American adults between the ages of 20 and 74 [2].Although some studies have suggested that pregnancy does not alter the course of diabetic retinopathy $[3,4]$, the majority have demonstrated the opposite to be true. [5].

In the most recent years, a number of studies have been published, reported reference values for ophthalmic artery and central retinal artery Doppler parameters throughout healthy pregnancy. [6,7]Different studies revealed two adverse results regarding the pregnancy effects on the ophthalmic artery Doppler indices $[6,8]$.The impedance indices and velocities are important for detecting changes in blood flow [9].Several studies have shown that women, who have had diabetes for a very long period of time, are more susceptible to worsening of their diabetic retinopathy during pregnancy [5].

Therefore, this study aimed to assess the ophthalmic artery Doppler indices values in all the pregnancy trimesters classes in Maternal typeldiabetic.To compare the findings between pregnant diabetic ladies with healthy non diabetic pregnant, and healthy non pregnant group, by measuring the mean velocity flow of ophthalmic artery, pulsatility index and resistivity index .To correlate the Doppler findings with the treatment type and its administrations in type 1 diabetic ladies. 


\section{Materials and Methods}

This study was performed during the period from July2012 to July2013.

\subsection{Sample}

The sample was divided into 3groups: group 1 included 15Pregnant Diabetic ladies: their ages were between (30-39) years old, $8(53.3 \%)$ out of 15 were under diet control, $7(46.7 \%)$ were insulin dependent, 14(93.3\%) used regular insulin treatment where $1(6.7 \%)$ uses the insulin in irregular manner. Group 2 were fourteen healthy pregnant ladies; their ages were between (30-37) years. Group 3 was the Control group and their ages were (30-41) years. Any patients with eyes disease, abnormal pregnancy or pregnancy with preeclampsia were excluded.

\subsection{Methods}

Color Doppler US High-frequency transducer (linear array transducer) (Voluson E6) was used. The scans were performed with the patient supine and eyes were closed. 7.5 MHZ ultrasound scanner were used and applied with contact jelly through the closed upper lid while examiner's hand rests upon the orbital margin to minimize the pressure on the globe. Horizontal scan through the eye and orbit was performed. Depending on the direction of flow with respect to transducer, the blood flow results were displayed in either red or blue. The ophthalmic artery Doppler indices including Resistivity index (RI), pulsatility index (PI), Mean Velocity (MV) were measured in all groups for right and left eyes.

\subsection{Data Analyses}

Data were collected using a data collection sheets.The results were registered in the first, second and third trimester for each pregnant lady and then analyzed using SPSS Program Version 16. T-test was used to compare means .Values were expressed as Mean $\pm \mathrm{SD}$; Significant at $\mathrm{P}$-value $<0.05$.

\section{Results}

Table 1. Doppler Indices Left Eye and Right Eye of 15 Pregnant type 1 Diabetic ladies

\begin{tabular}{llll}
\hline Doppler Indices Left Eye & & & \\
& RI & PI & MV \\
\hline First Trimester & $0.7 \pm 0.3$ & $1.2 \pm 0.7$ & $6.5 \pm 2.1$ \\
Second Trimester & $1.4 \pm 0.3$ & $3.2 \pm 0.7$ & $6.2 \pm 1.1$ \\
Third Trimester & $1.8 \pm 0.2$ & $4.5 \pm 0.9$ & $4.8 \pm 1.2$ \\
P-value & $0.000^{*}$ & $0.000^{*}$ & $0.009^{*}$ \\
Total & $1.3 \pm 0.5$ & $3.0 \pm 1.6$ & $5.8 \pm 1.7$ \\
Doppler Indices Right Eye & & & \\
& $\mathrm{RI}$ & PI & MV \\
First Trimester & $0.7 \pm 0.3$ & $1.4 \pm 0.6$ & $6.4 \pm 2.8$ \\
Second Trimester & $1.4 \pm 0.3$ & $3.3 \pm 0.7$ & $5.8 \pm 1.2$ \\
Third Trimester & $1.6 \pm 0.3$ & $4.9 \pm 0.4$ & $4.0 \pm 1.3$ \\
P-value & $0.000^{*}$ & $0.000^{*}$ & $0.005^{*}$ \\
Total & $1.2 \pm 0.5$ & $3.2 \pm 1.6$ & $5.4 \pm 2.1$ \\
\hline
\end{tabular}

Values are expressed as Mean $\pm \mathrm{SD} ;{ }^{*}$ Significant at $\mathrm{P}$-value $<0.05$.
Table 2. Doppler Indices of Left Eye and Right Eye and treatment as Diet control and Insulin

\begin{tabular}{llll}
\hline $\begin{array}{l}\text { Doppler Indices of Left Eye } \\
\text { Treatment }\end{array}$ & RI & PI & MV \\
\hline Diet Control & $1.5 \pm 0.1$ & $3.5 \pm 0.5$ & $5.6 \pm 0.7$ \\
Insulin & $1.4 \pm 0.2$ & $3.1 \pm 0.4$ & $5.8 \pm 1.0$ \\
P-value & 0.157 & 0.158 & 0.792 \\
Total & $1.4 \pm 0.2$ & $3.3 \pm 0.5$ & $5.7 \pm 0.8$ \\
Doppler Indices of Right Eye & & \\
Treatment & RI & PI & MV \\
Diet Control & $1.4 \pm 0.2$ & $3.6 \pm 0.5$ & $5.7 \pm 0.4$ \\
Insulin & $1.3 \pm 0.0$ & $3.3 \pm 0.0$ & $5.9 \pm 0.0$ \\
P-value & 0.383 & 0.758 & 0.201 \\
Total & $1.3 \pm 0.2$ & $3.6 \pm 0.4$ & $5.8 \pm 1.1$ \\
\hline
\end{tabular}

Values are expressed as Mean $\pm \mathrm{SD} ;{ }^{*}$ Significant at $\mathrm{P}$-value $<0.05$.

Table 3. Doppler Indices Left Eye and Right Eye of 14 healthy Pregnant ladies

\begin{tabular}{|c|c|c|c|}
\hline \multicolumn{4}{|c|}{ Doppler Indices of left Eye } \\
\hline & RI & PI & MV \\
\hline First Trimester & $0.5 \pm 0.2$ & $0.9 \pm 0.5$ & $8.1 \pm 2.0$ \\
\hline Second Trimester & $0.8 \pm 0.2$ & $1.7 \pm 0.5$ & $6.7 \pm 1.4$ \\
\hline Third Trimester & $0.6 \pm 0.2$ & $3.0 \pm 0.9$ & $5.7 \pm 1.0$ \\
\hline P-value & $0.002^{*}$ & $0.000^{*}$ & $0.001^{*}$ \\
\hline Total & $0.7 \pm 0.2$ & $1.9 \pm 1.1$ & $6.8 \pm 1.8$ \\
\hline \multicolumn{4}{|c|}{ Doppler Indices of Right Eye } \\
\hline & RI & PI & MV \\
\hline First Trimester & $0.6 \pm 0.2$ & $1.0 \pm 0.7$ & $8.1 \pm 3.4$ \\
\hline Second Trimester & $0.9 \pm 0.2$ & $1.8 \pm 0.8$ & $6.2 \pm 1.5$ \\
\hline Third Trimester & $1.3 \pm 0.3$ & $0.9 \pm 2.0$ & $5.1 \pm 1.5$ \\
\hline P-value & $0.000^{*}$ & $0.000^{*}$ & $0.006^{*}$ \\
\hline Total & $0.9 \pm 0.4$ & $2.0 \pm 1.1$ & $6.5 \pm 2.6$ \\
\hline
\end{tabular}

Values are expressed as Mean $\pm \mathrm{SD} ;{ }^{*}$ Significant at $\mathrm{P}$-value $<0.05$.

Table 4. Comparison between the three groups (Control, Pregnant type1Diabetic \& healthy pregnant ladies):

\begin{tabular}{lclll}
\hline $\begin{array}{l}\text { Doppler } \\
\text { Indices/Eye }\end{array}$ & Control & $\begin{array}{l}\text { Pregnant } \\
\text { Diabetic }\end{array}$ & $\begin{array}{l}\text { Pregnant } \\
\text { Normal }\end{array}$ & P-value \\
\hline Right Eye RI & $0.8 \pm 0.1$ & $1.3 \pm 0.2$ & $1.0 \pm 0.2$ & $0.000^{*}$ \\
Right Eye PI & $1.6 \pm 0.4$ & $3.6 \pm 0.4$ & $2.2 \pm 0.7$ & $0.000^{*}$ \\
Right Eye MV & $8.4 \pm 3.2$ & $5.2 \pm 1.1$ & $6.2 \pm 1.3$ & $0.001^{*}$ \\
Left Eye RI & $0.7 \pm 0.1$ & $1.4 \pm 0.2$ & $0.9 \pm 0.2$ & $0.000^{*}$ \\
Left Eye PI & $1.6 \pm 0.3$ & $3.3 \pm 0.5$ & $2.1 \pm 0.5$ & $0.000^{*}$ \\
Left Eye MV & $8.5 \pm 3.2$ & $5.7 \pm 0.8$ & $6.5 \pm 0.7$ & $0.001^{*}$ \\
\hline
\end{tabular}

Values are expressed as Mean $\pm \mathrm{SD} ;{ }^{*}$ Significant at P-value $<0.05$

\section{Discussion}

For diabetic pregnant ladies Mean RI ,PI ,MV were found to be $1.3 \pm 0.5,3.0 \pm 1.6,5.8 \pm 1.7$,for left eye and $1.2 \pm 0.5$, $3.2 \pm 1.6,5.4 \pm 2.1$ for right eye, Doppler Indices as RI ,PI were increased in the left and right eye significantly in second and third trimester at $p$ value $=0.000$, where MV were decreased significantly as seen in table[1]

Our study indicates that ophthalmic artery Doppler parameters in pregnant women at risk for diabetes are different from the reference values that have been reported from healthy pregnancies. $[6,10,11]$ The diabetic pregnant ladies were treated with insulin or diet control .The study showed that there was no significant difference between the type of treatment and (RI, PI \& MV) in left or right eye as 
seen in table [2]

Describing the effect of diabetes is that the elevated glucose levels are important factor leading to alterations of vessel architecture in the retina, flow irregularity, and development of the disease. Changes of retinal vessels include thickening of the capillary basement membrane, [12] Capillary hypo perfusion [13].These justify the increasing of $\mathrm{RI}$ and PI and reduction of MV.

Similar investigators have reported that blood flow velocities in the retro bulbar central retinal artery [14] and in branch retinal arteries are reduced [15].

Regarding the results, both pregnancy and diabetes can cause retinopathy, due to the noticeable changes of Doppler indices. Table [3] showed significant differences in the indices in the second and third trimester for right and left eyes in healthy pregnant ladies. During pregnancy, physiological changes occur in the vessels[16]pregnancy causes weakening in the retinopathy conditions in diabetic women, even when good metabolic control is achieved and retinopathy is minimal.[17,18]

The main finding of the study was that retinal mean blood flow velocity was 5.8 which is higher in women with insulin-dependent diabetes than in diet control. Similar results were found in previous studies. [19]

In contrast, no tendency towards an increase in mean retinal blood velocity flow was seen in the pregnant non diabetic ladies .In addition, a significant difference existed in Doppler indices of right and left eyes between pregnant non diabetic, and diabetic pregnant and control subjects as seen in table [4] whereas pregnant diabetic women had higher RI, PI values and lower MV values than did pregnant non diabetic and control subjects.

We noticed that pregnancy itself may cause retinopathy. This consigned to what was stated that after accounting for glycemic control, the pregnancy state itself was a major risk factor of retinopathy. [20] Various factors have been shown to influence the progression of diabetic retinopathy during pregnancy. These included the pregnant state itself, duration of diabetes prior to the pregnancy, degree of retinopathy at time of conception, metabolic control before and during pregnancy, as well as the presence of coexisting hypertension [23].These results showed similar findings done by Schocket et al.[22]who found a decrease in retinal volumetric blood flow during the third trimester in both diabetic and non diabetic mothers, with larger significant decrease in diabetics. This group speculate the progression of diabetic retinopathy.[23]

\section{Conclusion}

Readings of Ophthalmic artery Doppler indices (resistive index (RI), pulsatility index (PI)) for type 1diabetes ladies were found to be greater when compared with reference values mentioned in the literature and the control group values and Mean Velocity (MV) was of lower values. The study recommended to consider changes RI and PI values in all the pregnancy periods which reflect the critical phase that exist before the clinical development of diabetic retionopathy in pregnant ladies with type1diabetic.Our agreements were consistent with the recommendations of the American Diabetes Association [23] which recommend that women with preexisting diabetes who are planning a pregnancy should have a comprehensive eye examination and be counseled on the risk of development and/or progression of diabetic retinopathy.

\section{Acknowledgements}

Our Thanks to Sudan University of Science and Technology, College Of Medical Radiological Science.

\section{References}

[1] S.J. Erickson, L.E. Hendrix, B.M .Massaro, et al. Color Doppler flow imaging of the normal and abnormal orbit. Radiology 1989; 173:511-516

[2] MMWR. Blindness caused by diabetes-Massachusetts, $1987-$ 1994. MMWR-Morbidity \& Mortality Weekly Report 45: 937-941; 1996

[3] C, Bruttomesso D, Fedele D. Pregnancy does not induce or worsen retinal and peripheral nerve dysfunction in insulindependent diabetic women. J Diabetes Complications 12: $74-80 ; 1998$

[4] M .Lovestam-Adrian, C. D. Agardh, A. Aberg, E .Agardh. Preeclampsia is a potent risk factor for deterioration of retinopathy during pregnancy in type I diabetic patients. Diabet Med. 14: 1059-1065; 1997.

[5] R.C .Temple, V.A.Aldridge, M.J .Sampson, R.H. Greenwood, P.J .Heyburn, A. Glenn. Impact of pregnancy on the progression of diabetic retinopathy in type I diabetes. Diabetic Medicine 18:573-577; 2001

[6] R.S .Carneiro, N. Sass, A.L. Diniz, E.V. Souza, M.R. Torloni, A.F. Moron. Ophthalmic artery Doppler velocimetry in health pregnancy. In J Gynaecol Obstet 2008; 100:211-215

[7] F .Mackenzie, R. De Vermette, C .Nimrod, D .Boisvert, B .Jackson. Doppler sonographic studies on the ophthalmic and central retinal arteries in the gravid woman. J Ultrasound Med 1995; 14:643-647 (references)

[8] Y. Ohno, M. Kawai, Y.Wakahara, T .Kitagawa, M .Kakihara, Y. Arii. Ophthalmic artery velocimetry in normotensive and preeclamptic women with or without photophobia. Obstet Gynecol 1999; 94:361-363.

[9] R.S .Tompson, B.J .Trudinger, C.M. Cook. Doppler ultrasound waveform indices: $\mathrm{A} / \mathrm{B}$ ratio, pulsatility index and Porcelot ratio. Br J Obstet Gynaecol 1988; 95:581-588

[10] A.L. Diniz, A.F .Moron, M.C .Santos, C.R. Pires. Doppler velocimetria das artérias oftálmica e central da retina em gestantes normais. Rev Bras GinecolObstet 2005; 27: $168-173$.

[11] F .Mackenzie, R .De Vermette, C. Nimrod, D. Boisvert, B. Jackson. Doppler sonographic studies on the ophthalmic and central retinal arteries in the gravid woman. $J$ Ultrasound Med 1995; 14:643-647 
[12] J. Cai, M. Boulton. The pathogenesis of diabetic retinopathy: old concepts and new questions. Eye 2002;16:242-260

[13] L .Schmetterer, M. Wolzt. Ocular blood flow and associated functional deviations in diabetic retinopathy. Diabetologia 1999;42:387-405

[14] T .Kawagishi, Y .Nishizawa, M .Emoto, $\mathrm{T}$.Konishi, K .Maekawa, S .Hagiwara, Y .Okuno, H .Inada, G .Isshiki, H. Morii. Impaired retinal artery blood flow in IDDM patients before clinical manifestations of diabetic retinopathy. Diabetes Care 1995;18:1544-1549

[15] G.T .Feke, S.M .Buzney, H. Ogasawara, N.Fujio, D.G. Goger, N.P. Spack, K.H .Gabbay. Retinal circulatory abnormalities in type 1 diabetes. Invest Ophthalmol Vis Sci 1994; 35: 2968-2975

[16] K.L .Thornburg, S-L .Jacobson, G.D .Giraud, M.J. Morton. Hemodynamic changes in pregnancy. Semin Perinatol. 2000; 24:11-14.

[17] G .Soubrane, J .Canivet, G .Coscas. Influence of pregnancy on the evolution of background retinopathy: preliminary results of a prospective fluorescein angiography study. Int Ophthalmol Clin. 1985; 8: 249-255
[18] T. Hellstedt, R. Kaaja, K .Teramo, I. Immonen. Macular blood flow during pregnancy in patients with early diabetic retinopathy measured by blue-field entoptic simulation. Graefes Arch Clin ExpOphthalmol. 1996; 234: 659-663.

[19] Sirpa Loukovaara, Mika Harju, Risto Kaaja, and Ilkka Immonen. Retinal Capillary Blood Flow in Diabetic and Non diabetic Women during Pregnancy and Postpartum Period IOVS, April 2003, Vol. 44, No. 4,1486-1491

[20] The Diabetes Control and Complications Trial Research Group. Effect of pregnancy on micro vascular complications in the Diabetes Control and Complications Trial. Diabetes Care 23:1084-1091; 2000 .

[21] Jeff Van Impe, Pregnancy and Its Effect on the Progression of Diabetic Retinopathy 2005 8(2): 142-8

[22] L. S .Schocket, J.E. Grunwald, A.F. Tsang, J .DuPont. The effect of pregnancy on retinal hemo dynamics in diabetic versus non diabetic mothers. Am J Ophthalmol. 128(4): 477-484; 1999

[23] L.P. Aiello, T.W .Gardner, G.L. King, Blankenship G, J.D. Cavallerano, Ferris FL 3rd, Klein R. Diabetic retinopathy. American Diabetes Association: Position Statement. Diabetes Care 23:S73-S76; 2000. 